\title{
3 Research Square

\section{Prevalence of Hepatitis B virus and its predictors among volunteer blood donors in Jimma, Ethiopia, 2018}

\section{Tesfaye Solomon ( $\square$ abdiikoo50@gmail.com )}

Ethiopian Public Health Institute https://orcid.org/0000-0003-0994-393X

\section{Debele Mekonnen}

Jimma Blood Bank Center, Jimma, Ethiopia

Mamo Nigatu

Department of Epidemiology, Jimma University, Ethiopia https://orcid.org/0000-0002-8473-9771

\section{Research Article}

Keywords: Hepatitis B virus, prevalence, predictors, volunteer blood donors, Ethiopia

Posted Date: June 3rd, 2021

DOI: https://doi.org/10.21203/rs.3.rs-587485/v1

License: (c) This work is licensed under a Creative Commons Attribution 4.0 International License.

Read Full License 


\section{Abstract}

Background: Transfusion of contaminated blood causes a significant burden of Hepatitis B virus (HBV) infection globally and more than 45,000 infections in Sub-Saharan Africa annually. However, very few studies were conducted in Ethiopia to assess the status of HBV.

Objective: To determine the prevalence of HBV and its predictors among volunteer blood donors in Jimma Zone, Southwest Ethiopia.

Material and Methods: A cross-sectional study was conducted among volunteer blood donors who consecutively included from March 10 - April 20, 2018. The detection of the virus was made through the investigation of the Hepatitis B surface antigen in the serum. Data collected through a structured questionnaire were entered into Epi-data 3.1 and analyzed by SPSS 20. Adjusted Odds Ratio with 95\% Confidence Interval computed using multivariable logistic regression and statistical significance established at $\mathrm{P}<0.05$.

Results: A total of 548 (98.7\%) volunteer blood donors participated. The overall prevalence of HBV infection was $16(2.92 \%)$ with $12(4.5 \%)$ and $4(1.4 \%)$ prevalence among males and females respectively. Male sex [AOR=3.28, 95\% Cl: $1.01-10.68]$, age $18-24$ years [AOR=0.17, $95 \% \mathrm{Cl}: 0.36-0.78]$, frequency of donation $[A O R=0.25,95 \% \mathrm{Cl}: 0.08-0.76]$ and exposure to unsafe therapeutic drug injection [AOR=6.98, 95\% Cl: 1.66-29.29] were significant factors for HBV infection.

Conclusions: The prevalence of HBV in the study area was intermediate. Age, sex, frequency of donation, and exposure to unsafe therapeutic drug injection were independent predictors of HBV. Therefore, the blood bank should focus on blood donation among identified low-risk groups and should strengthen counseling for repeated volunteer blood donors.

\section{Background}

Hepatitis B infection which is caused by a DNA virus of the family Hepadnaviridae, Hepatitis B virus (HBV), is one of the most common infectious diseases in the world and a major health problem (1). It is about 50 to 100 times more infectious than the Human Immunodeficiency Virus (HIV) and 10 times more infectious than hepatitis $\mathrm{C}$ virus (HCV). Chronic infection with $\mathrm{HBV}$ is a common cause of death associated with liver failure, cirrhosis and liver cancer (2-4). Hepatitis B is a silent killer disease of the liver with many carriers not aware of their clinical status, therefore, they act as a potential source of infection to other seronegative people (5).

The presence of Hepatitis B surface antigen ( $\mathrm{HBsAg})$ in the blood indicates that an individual is currently infected with the virus. Individuals who recover from acute hepatitis $B$ infections clear the blood off HBsAg within approximately four months after the onset of symptoms. These individuals develop antibodies to HBsAg (anti-HBs) that provides complete immunity to subsequent hepatitis B viral infection. 
Similarly, individuals who are successfully vaccinated against hepatitis produce anti-HBsAg in the blood (6).

The risk of developing Chronic Hepatitis $B(\mathrm{CHB})$ virus infection commonly defined as being positive for hepatitis B surface antigen (presence of HBsAg in the blood) for greater than 6 months is inversely related to the age of acquisition of the infection. Generally, the risk of chronic HBV infection is $90 \%$ following infants infected at birth while the risk is put at $30 \%$ for children infected between 1 and 5 years of age, and only about $1-5 \%$ for those infected as older children and adults (7).

The main routes of HBV transmission are by percutaneous or mucosal exposure to infected blood and various body fluids, as well as through saliva, tears, menstrual, vaginal, and seminal fluids. Transmission of the virus may also occur through the reuse of needles and syringes either in health-care settings or among persons who inject drugs. Also, the infection can occur during medical, surgical and dental procedures, through tattooing, or through the use of razors and similar objects that are contaminated with infected blood (8).

Worldwide, it is estimated that 240 million people are chronically infected with HBV (9). Recent reports demonstrated that 68,600 people die of HBV infection and more than 300,000 deaths due to liver cancer secondary to hepatitis B every year globally (10). The prevalence of chronic HBV infection worldwide could be categorized as high if it is higher than $8 \%$, intermediate if it is between $2 \%$ and $7 \%$, and low endemicity if it is below $2 \%$ (11). Overall, approximately $45 \%$ of the global populations live in areas of high chronic HBV prevalence (12). The prevalence of HBV is estimated at $8 \%$ in West Africa and $5-7 \%$ in Central, Eastern and Southern Africa(12). Ethiopia, being part of this region, is ranked within an area with medium to high endemicity for HBV $(13,14)$.

According to the World Health Organization (WHO) reports, the prevalence of HBV infections among blood donors in different parts of the world varies from $0.008 \%$ to $6.08 \%$ (9). Among voluntary, nonremunerated blood donors recruited with effective education and selection programs, the prevalence and incidence of HBV infection should be lower than in the general population. Despite a lower prevalence and incidence, screening of blood donors may lead to tests that are positive for HBV infection $(15,16)$.

Globally, transfusion of contaminated blood causes up to 16 million new infections with HBV. With each blood unit transfused, there is always a $1 \%$ likelihood of transfusion-linked risks including transfusiontransmitted infections $(17,18)$. Globally, an estimated 1.6 million blood units are discarded annually due to the presence of markers for transfusion-transmitted infections, including HIV, HBV, HCV, and syphilis (16).

In Sub-Saharan Africa, $12.5 \%$ of patients who received blood transfusion are at risk of post-transfusion hepatitis (19). It is estimated that more than $45,000 \mathrm{HBV}$ infections are transmitted through contaminated transfusions annually(20). From 2000 to 2011, the number of countries in sub-Saharan Africa screening at least $95 \%$ of donated blood units for HBV increased from $76 \%$ to $94 \%$. During the same period, the median percentage of HBV marker-reactive units decreased from $7.1 \%$ to $4.4 \%$ (21). 
In Ethiopia, it was estimated that over 5 million people are living with chronic HBV infection among the general population (6). Several programs have been implanted in Ethiopia to reduce the burden of HBV in the community. These programs includes: the Expanded Program on Immunization policy including childhood immunization against HBV using a pentavalent form at ages 6, 10 and 14 weeks after birth; implementing antenatal screening for HBsAg of all pregnant women and the vaccination of their babies at birth; and recommending the vaccination of high risk groups such as health professionals against HBV. However, these programs have not been routinely enforced in most healthcare settings across the country (22).

Quality-guaranteed screening of all donated blood for transfusion-transmitted infections (TTIs) including $\mathrm{HIV}, \mathrm{HBV}$, and $\mathrm{HCV}$, is recommended by the WHO and adopted by the Ethiopian government for the provision of safe and efficacious blood and blood components (8). In response to this strategy, Ethiopia takes responsibilities for blood transfusion from the Ethiopian Red Cross Society and granted it to the national blood transfusion service Agency, a government agency managed under the Federal Ministry of Health and Regional Health bureau created in 2010 to ensure blood safety and accessibility (23). A crosssectional retrospective record review conducted in Jimma Blood Bank Center from 2010 to 2015 shows the prevalence of HBV $3.05 \%$ (24).

Previous studies conducted on the prevalence of HBV infection and its predictors among blood donors in Ethiopia were focused on all types of donors including family replacement blood donors and commercial blood donors in which the prevalence of HBV is high due to absence of exposure screening before blood donation.

Therefore, this study was aimed to determine the prevalence of HBV and associated factors among volunteer blood donors in Jimma zone, which will contribute as an input for prevention and control of the hepatitis $B$ virus infection, assuring blood safety in achieving the national blood transfusion services strategies and improving blood donor selection protocol according to the geographic area and population subgroup.

\section{Methods}

\section{Study setting}

The study was conducted in the Jimma zone, Oromia Regional State which is located at a distance of $354 \mathrm{~km}$ away from Addis Ababa to the Southwest part of Ethiopia. According to the data from the Jimma Zone Statistical Department in 2017, the zone has an estimated 3,174,484 total population. It has 21 districts with a total of 555 villages. In the zone, there is a branch of national blood transfusion service agency providing blood donation services to the hospitals.

\section{Study design and period}


A cross-sectional study was conducted in Jimma Zone among volunteer blood donors who visited the blood bank and blood collection sites for donating blood during study period, have lived in the zone for the last six months and were qualified for blood donation according WHO blood bank guidelines for blood donation eligibility criteria's (8). Blood donors who refused to give informed consent were excluded. Data were collected from March 10 to April 20, 2018.

\section{Study variables}

Dependent variable: HBV infection status

The independent variables were;

Socio-demographic factors: Age, sex, marital status, educational status, residency, occupation

Behavior related factors: Razor and sharp material sharing, unprotected multiple sexual activities, tattooing, ear/nose piercing, using unsafe therapeutic drug injection, number of blood donation

Knowledge related factors: Knowledge about the causative agent, means of transmission, sign and symptoms and treatment of HBV

Treatment-related/clinical factors: Blood transfusion, surgical procedure, dental procedure, HB vaccination status, previous history of hospitalization

\section{Sample size determination}

The sample size was calculated manually using a single population proportion formula by taking the prevalence of HBV among blood donors in the Southwest Ethiopia 3.05\% (24), 1.5\% margin of error and $95 \%$ confidence interval $(\mathrm{Cl})$. Assuming a $10 \%$ non-response rate, the final sample was 555 . The prevalence of HBV among blood donors gives the largest sample size than factors associated with it and so used to determine the final sample size.

\section{Sampling techniques}

All volunteer blood donors were selected consecutively from the collection sites in Jimma zone and blood bank center during the study period until the required sample obtained. Sampling procedure follows the movement plans of blood bank service due to the data collectors assigned with each team of blood bank staff. Three functional teams established to collect blood from volunteer blood donors. Each team planned to collect 250 blood units within ten days at blood bank center and fifteen days outreach since the number of volunteers in each planned collection site usually unknown. So, the sample size was equally distributed for case teams. After community mobilization, the data collectors moved for blood collection to the planned collection sites with blood bank staffs. 


\section{Data collection tool and techniques}

Data were collected by a structured questionnaire adapted from previous different literature $(8,24)$ and it was numbered to identify those who had to respond and/or not. The questionnaire was originally prepared in English and translated into the local language, Afan Oromo and Amharic, for fieldwork purposes and back to English for checking language consistency.

After donors agreed to take part in the study, he or she signed a consent form and data collectors collect baseline information of each participant. Then, the blood sample was taken from blood bags of donated blood to sterile test tubes which further used for the screening with a closed system. Then the collected blood was centrifuged, plasma separated and stored at 2 to $8^{\circ} \mathrm{C}$ until it was tested. Samples were brought to room temperature before testing. The plasma sample was performed and analyzed for HBsAg using the $4^{\text {th }}$ generation Enzyme-Linked Immune Sorbent Assay (ELISA) test kit by a senior laboratory professional in the blood bank.

\section{Data quality assurance}

Data collectors were selected based on the ability to speak the local language and two days orientation was given by the investigators on the objective, process of data collection and field ethics. The whole data collections were supervised by the investigators.

Each questionnaire was cross-checked daily by the investigators for completeness and consistency. ELISA kits were checked for appropriate storage conditions and its expiry date. Internal positive and negative controls were included in each assay run and standard operation procedures and manufacturer instructions were strictly followed.

A pretest was conducted in a nearby zone taking $5 \%$ of the total sample to test the data collection tool. Consequently, clarifications and corrections were made on problems encountered about the questionnaire.

\section{Data analysis}

Each questionnaire was coded and checked manually for completeness, consistency, and clarity. Then, the coded and cleaned data were entered into Epidata 3.1 and exported to SPSS version 20.0 where statistical analyses were done. Descriptive analyses were done to determine the prevalence of HBV. Bivariate analysis was done to select candidate variables with $P<0.25$. Then entered into multivariable analysis to identify independent predictor variables and control for confounders. Finally independent variables at $\mathrm{P}<0.05$ level of significance with Adjusted Odds Ratio (AOR) and its $95 \%$ Confidence Interval $(\mathrm{Cl})$ in multivariable logistic regression were used to identify statistical significance. 


\section{Operational definition}

Knowledge about HBV prevention and control was measured using 18 questions that include general awareness about HBV, mode of transmission, sign and symptoms, complications and treatment based on the current literature. Each correct answer scored 1 and wrong answer or "I don't know" scored 0 . Thus the knowledge score was scaled from 0 to 18. A person scoring a total of 9 or less was taken as having poor knowledge and those scoring 10 and above had good knowledge.

\section{Results}

\section{Socio-demographic characteristics}

A total of $548(98.7 \%)$ volunteer blood donors were participated in the study. The age of respondents ranges from 18 to 51 years with the mean age of 24.84 years and Standard Deviation (SD) of \pm 5.85 years. The majority of the $334(60.9 \%)$ were found in the age group of $18-24$ years and $330(60.2 \%)$ were students in occupation (Table 1).

\section{Knowledge of the respondents}

Among 548 participants, 443 (80.84\%) respondents had good knowledge about HBV and the majority, $248(45.3 \%)$ get the information from health professionals.

\section{Prevalence of HBV}

The detection of HBV was made through the investigation of HBsAg in the serum. The overall prevalence of HBsAg among volunteer blood donors who participated in this study was $16(2.92 \%)$ and the seropositivity was higher in male participants $12(4.5 \%)$.

The prevalence of HBsAg was higher among volunteer blood donors aged $\geq 35$ years. The highest occupation-specific prevalence of HBsAg was observed among the daily laborer (4.8\%) and lowest prevalence was seen among students $(2.1 \%)$ (Table 2).

\section{Prevalence of HBV by clinical exposures}

Concerning the distribution of HBsAg positivity by clinically related exposures, 36(6.6\%) of the respondents had a history of hospitalization and 12(2.2\%) of them had an exposure history of blood transfusion. The seropositivity among those hospitalized and exposed was $2(5.6 \%)$ and $1(8.3 \%)$ respectively. The majority of respondents $502(91.6 \%)$ were not vaccinated for the Hepatitis B virus and they took a higher prevalence of HBsAg 15(3.0\%) as compared to those vaccinated. 


\section{Prevalence of HBV by behavioral and knowledge factors}

Forty-four (8.0\%) of study participants were using a razor and other sharp materials together and 19(3.5\%) had multiple sexual partners. Among those participants, the prevalence of HBsAg was 2(4.5\%) and $1(5.3 \%)$ respectively. While $23(4.2 \%)$ of study participants were exposed to unsafe therapeutic drug injection and their seropositivity for HBsAg was $3(13.0 \%)$ which was higher than those who were not exposed, however, it was not statistically significant.

Of 548 study participants, 313(57.1\%) donated blood twice and more times. The prevalence of HBV infection was higher $11(4.7 \%)$ among first-time volunteer blood donors and blood donors with poor knowledge 4(3.8\%).

\section{Predictors of Hepatitis B Viral Infection}

Those candidate variables with P-value $<0.25$ in bivariate logistic regression were entered in multivariable logistic regression models to control for confounders and to evaluate the net effects of risk variables on hepatitis B viral infections among the studied group and considered as significant in the model if the Pvalue less than 0.05 .

Being male was found to be an independent predictor of Hepatitis B Viral Infection. Male volunteer blood donors were about three times more seropositive for HBV infection than female donors [AOR=3.28, 95\%Cl: 1.01-10.68].

Age group is also found to be a risk factor for Hepatitis B viral infection. Blood donors within the age group 18-24 were $83 \%$ less likely seropositive for HBV infection than those age group $\geq 35$ years old [AOR=0.17, 95\% Cl: 0.36-0.78].

The number of blood donation was identified as a predictor variable for HBV infection. Volunteer blood donors who were donated blood more than once were about $75 \%$ less likely seropositive for HBV infection than first-time donors [AOR=0.25, 95\% Cl: 0.08-0.76].

History of exposure to unsafe therapeutic drug injection was an independent predictor of HBV infection. Volunteer blood donors who exposed to unsafe therapeutic drug injection were about seven times more likely to seropositive for HBV infection than those who were not exposed [AOR=6.98, 95\%Cl: 1.66-29.29] (Table 3).

\section{Discussion}

In this study the proportion of male and female volunteer blood donors were approximately equal $268(48.9 \%)$ and $280(51.1 \%)$ in contrast to the previous studies from some parts of Ethiopia that showed majority of blood donors were male donors; $87.9 \%$ in Gondar (25), $74.6 \%$ in Wolaita (26) and $98.7 \%$ in 
Jigjiga (27). This may show that the awareness of males and females became comparable concerning blood donation due to the majority of current study participants were students.

The majority of the participants 334(60.9\%) were aged between 18-24 years. The findings of this study partly agreed with a study conducted in Hawasa 86.2\% (28), in Arba Minch 80.2\% (29) and with that of WHO report that $45.0 \%$ of blood donors aged 25 or less (16). This indicated that routine blood bank activities were targeted on donors of a younger age, mostly high school and college students, as this group is perceived to be more willing to donate blood and also a low-risk group.

The prevalence of HBsAg among volunteer blood donors in the study area was 16(2.92\%). Based on the WHO classification of HBV endemicity which based on the seropositivity rate of HBsAg, this result indicates the study area is categorized in an intermediate endemicity to HBV infection $(5,8)$. This finding also in line with a retrospective study conducted in Jimma Blood Bank from 2010 to 2015 that revealed HBsAg prevalence among blood donors was 3.05\%(30).

The prevalence of HBsAg in this study was higher than researches conducted in Eritrea 2.58\%, Egypt 2.3\% and India 1.94\% (31-33). This is probably because of the differences in social, behavior, lifestyle, socioeconomic status and level of awareness in different countries. In contrast, it is lower than the study conducted in Yemen 5.1\%, Cameroon 11.2\%, and Nigeria 9.3\% (34-36). This might be because most of the study participants in the previous study were family replacement and commercial blood donors whereas only volunteer blood donors were included in this study.

Similarly, the prevalence of HBV infection in this study was lower when compared with similar studies conducted in Ethiopia, national wide 3.9\% (37); Bahir Dar 4.1\% (38), Wolaita Sodo 9.6\% (26), and Arba Minch $4.7 \%$ (29). This might be due to the previous studies that include replacement type of blood donation and a higher number of first-time blood donors. Although, some possible differences in specificity and sensitivity of screening tests used at different sites during the time of screening might also explain in-part for the observed variations.

Being a male donor was about three times more likely to have HBV infection than a female donor. This finding was consistent with other studies previously conducted in Gondar, Dire Dawa and Jimma (25, 39, 40). This association might be attributed to cultural practices that could expose to HBV infection like circumcision using non-sterile equipment and while in male beauty salons which may use unsterilized barbing utilities.

Participants in the age group 18-24 years were about $83 \%$ less likely to have HBV infection than those who were in the age group $\geq 35$ years. This result in line with studies conducted in Jimma Blood Bank from 2010 to 2015 and in Gonder in $2010(25,29)$. Similarly, studies conducted in India and Nigeria shows the prevalence of hepatitis $B$ higher among $\geq 35$ years and has a significant statistical association with Hepatitis $B$ infection $(33,36)$. This might be due to youths between 18 and 24 years of age group is less exposed to risk factors like occupational risk and unsafe sex. 
Participants who had a previous history of blood donation were about $72 \%$ times less likely to seropositive for HBV infection than those first-time donors. This finding also in line with other studies conducted in Gonder where the prevalence of HBV among the first-time donor is about two times more likely to have HBsAg infection than repeated donor and Yemen where first time donor had 22 times more likely to have HBsAg infection than the repeated donor $(25,34)$. This might be due to most new donors have not been previously tested for markers of infections that used to exclude individuals from the donor population and repeated donors get awareness about the disease transmission.

Donors who exposed to unsafe therapeutic drug injection were about seven times more likely to have HBV infection than those who were not exposed. This study finding was in line with the studies conducted in Arba Minch (29) and Jimma University Specialized Hospital (40), and also in agreement with that of WHO reports in developing countries, contaminated injections caused an estimated 21 million HBV infections worldwide in 2000 , accounting for $32 \%$ of all new infections (5). This might be due to the therapeutic injection giver using contaminated syringes or other materials and unsafe procedures.

The majority of potential risk factors included in this study were not significantly associated with HBV infection. This might be due to the homogeneity of the study population as the majority of participants were young students.

\section{Limitation Of The Study}

The sero-markers used for assessment of HBV infection were not complete; HBV DNA was not detected by polymerase chain reaction due to the unavailability of resources, which might increase the detection rate of HBV and hence increase prevalence. Recall bias might be introduced due to previous exposure history solicited.

\section{Conclusions}

The prevalence of HBV infection with positive tests for HBsAg among volunteer blood donors in Jimma was $2.92 \%$. The prevalence of HBsAg is found to be intermediate prevalence according to the WHO hepatitis B endemicity category. The finding of this study indicated that low-risk volunteer blood donors were female, repeated donors and age group below 25 years. Thus, the blood bank should focus on blood donation among identified low-risk groups and should strengthen repeated volunteer blood donors to ensure the safety of blood for the recipient and to prevent HBV infection.

\section{Declarations}

\section{Acknowledgments}

We want to express our heartfelt thanks to our study participants, data collectors and Jimma Blood Bank as without their contributions the study will not be realized. 


\section{Authors' Contributions}

DM developed the proposal, carried out data collection, conducted the analysis, involved in reviewing the manuscript and had full access to all the data in the study. TS provided general guidance on overall study progress, participated in reviewing the proposal, reviewing the analysis, developing the final manuscript document, and had final responsibility for the decision to submit for publication. MN involved in interpretation of data, drafting and reviewing the manuscript. All the authors read and approved the final manuscript.

\section{Funding}

The authors declared no funding was received.

\section{Ethical approval and consent to participate}

Ethical approval for this study was obtained from the Institutional Review Board of Jimma University, Institute of Health Sciences. A permission letter was obtained from Jimma Blood Bank service center. Written informed consent was obtained from each participant. All blood donors who were positive for HBsAg during the study period were counseled by nurses assigned for counseling in the Blood Bank and linked to Jimma University Medical Center.

\section{Consent for publication}

The study participants were informed that finding of the study would published. Identifying images or clinical details of participants that compromise anonymity were not applicable in this manuscript.

\section{Competing interests}

We declare that the study has no competing interests.

\section{References}

1. Shepard CW, Colin W. Shepard, Edgar P. Simard, Lyn Finelli, Anthony E. Fiore, Beth PB. Hepatitis B virus infection: Epidemiology and Vaccination. 2006; Vol. 28.

2. Weinbaum CM, William I, Mast EE, Wang SA, Finelli L, Wesley A, et al. Recommendations for identification and public health management of persons with chronic hepatitis $B$ virus Infection. Morbidity and Mortality Weekly Report 2008;57:1-20.

3. F.Xavier Bosch, Mireia Díaz, Clérie R. Primary liver cancer: worldwide incidence and trends. Gastroenterology 2004127 5-16.

4. Pungpapong S KW, JJ P. Natural history of HBV infection: . Mayo Clin Proced an update for clinicians 2007;82:967-75.

5. WHO. Prevention \& Control of Viral Hepatitis Infection: Framework for Global Action. 2012. 
6. Mary D. Nettleman, MS, MACP. Facts about hepatitis B. Available from: https://www.emedicinehealth.com/hepatitis_b/article_em.htm

7. Yazigi N, BWVhIKR, Behrman RE, Jenson HB, (eds) ea. Nelson Textbook of Pediatrics. $18^{\text {th }}$ edn. Philadelphia: Saunders Elservier. 2007:1680-90.

8. WHO. Blood donor selection: guidelines on assessing donor suitability for blood donation. 2012.

9. WHO. Hepatitis B Fact sheet no 204. 2015.

10. Abubakar I, Tillmann T, Banerjee A. Global, regional, and national age-sex specific all-cause and cause-specific mortality for 240 causes of death, 1990-2013: a systematic analysis for the Global Burden of Disease Study. Lancet 2015 385(9963):p.117-71.

11. WHO. Hepatitis $B$ vaccines. Weekly epidemiological record; Hepatitis $B$ vaccines World Health Organization, Geneva, Switzerland 2009; 40: p. 405-20.

12. Wang Z, Zhang J, Yang H, Li X, Wen S, Guo Y, et al. Quantitative analysis of HBV DNA level and $H B e A g$ titer in hepatitis $B$ surface antigen positive mothers and their babies: HBeAg passage through the placenta and the rate of decay in babies. Journal of medical virology 2003;71(3):p. 360-6.

13. Mast EE, Weinbaum CM, Fiore AE, Alter MJ, Bell BP, Finelli L, et al. A comprehensive immunization strategy to eliminate transmission of hepatitis $B$ virus infection in the United States. Recommendations of the Advisory Committee on Immunization Practices (ACIP) Part II: immunization of adults 2006.

14. El-Raziky MS, E.-H.M., Salama KM, El-Hennawy AM, Helmy HM, Fahmy ME, et al. Patterns of hepatitis $B$ infection in Egyptian children in the era of obligatory hepatitis B vaccination. Arab J Gastroenterol 2012 13(1):p. 1-3.

15. WHO, CDC, IFRC. Blood donor counseling: implementation guidelines. 2014

16. WHO. Global Hepatitis Report. 2017.

17. Arora D, Arora B, A K. Seroprevalence of HIV, HBV, HCV and syphilis in blood donors in Southern Haryana. Indian Journal of Pathology and Microbiology 2010 53(2):p. 308-9.

18. Hutin Y KM, Dore GJ, Perz JF, Armstrong G, Dusheiko G et al. Global burden of disease (GBD) for hepatitis C. J Clin Pharmacol 2004;44:p. 20-9.

19. F. A. Fasola and I. A. Otegbayo. "Post-transfusion viral hepatitis in sickle cell anaemia: retrospectiveprospective analysis" Nigerian Journal of Clinical Practice 2002;5(1):p. 16-9.

20. Kafi-abad SA, R.H., Abolghasemi H, Talebian A. . Prevalence and trends of human immunodeficiency virus, hepatitis B virus, and hepatitis C virus among blood donors in Iran, 2004 through 2007. Transfusion 2009 49:p. 2214-20.

21. CDC. Progress toward Prevention of Transfusion-Transmitted Hepatitis $B$ and Hepatitis C Infection Sub-Saharan Africa, 2000-2011. . MMWR 2014 63(29): p. 613-41.

22. FDRE, FMoH. National expanded programme on immunization comprehensive multi-year plan 20112015.

23. WHO. Blood Safety in Ethiopia, WHO Regional office for Africa. 2014. 
24. Kebede W, Mekonnen Z, Gerbi A, G A. Transfusion-transmissible infection surveillance among blood donors in Southwest Ethiopia: A six years retrospective study. Asian Pac J Trop Dis 2017 7(3):p. 15661.

25. Tessema B Y.G., Kassu A, Amsalu A, A M. Seroprevalence of HIV, HBV, HCV and syphilis infections among blood donors at Gondar University Teaching Hospital, Northwest Ethiopia: declining trends over a period of five years. BMC Infectious Diseases 2010(10):111-8.

26. Bisetegen FS, Bekele FB, Ageru TA, FW W. Transfusion transmissible infections among voluntary blood donors at Wolaita Sodo University Teaching Referral Hospital, South Ethiopia. Canadian Journal of Infectious Diseases and Medical Microbiology 2016.

27. Mohammed Y., and, Bekele A. Seroprevalence of transfusion transmitted infection among blood donors at Jijiga blood bank, Eastern Ethiopia: retrospective 4 years study. BMC Res Notes 2016;9(1): 129.

28. B.Fisseha, H.M., A.Jemal, G.Daniel, B.Misganaw. The prevalence of transfusion transmitted infections in Hawasa Blood bank. International Journal of Blood transfusion and Immunohematology 2017(7).

29. Adalo, A. Prevalence and Associated Risk Factors of Hepatitis B and $C$ Virus among Volunteer Blood Donors in Arbaminch Blood Bank, SNNPR, Ethiopia. Journal of Medical Laboratory and Diagnosis May, 2016. ;7((4)):p. 20-7.

30. Kebede W., M.Z., Gerbi A., Abebe G. Transfusion-transmissible infection surveillance among blood donors in Southwest Ethiopia Asian Pac J Trop Dis2017 7((3)):p. 156-61.

31. Fessehaye N, Naik D, T. F. Transfusion transmitted infections-A retrospective analysis from the National Blood Transfusion Service in Eritrea. Pan African Medical Journal 2011;9(1).

32. Nada HA, M A. Seroprevalence of HBV, HCV, HIV and syphilis markers among blood donors at Suez Canal University Hospital Blood Bank in Egypt. J Blood Disorders Transf 2013;5(1):177-81.

33. Suresh B Sonth, Shilpa Gokale, Hadapad D, Solabannavar aSS. Prevalence of Hepatitis B Virus Infection among Blood Donors. IntJCurrMicrobiolAppSci 2015 4(10):p. 915-8.

34. Al Waleedi AA, Khader YS. Prevalence of hepatitis $B$ and $C$ infections and associated factors among blood donors in Aden city, Yemen. EMHJ 2012 18(6).

35. Nwobegahay J.M. , N.P.A., Kengne M., Roger Ayangma C., Abeng E.M., and NA, et al. Prevalence of Hepatitis $B$ virus infection among blood donors at the Yaounde Military Hospital, Cameroon. Microbiology Research International April 2016;4((2)):p. 6-10.

36. Augustine O., I.U., Wase A., Festus O., Osaro E, Hauwa B., et al. Prevalence of transfusion transmissible hepatitis B infection among blood donors in Sokoto, North Western, Nigeria Health Sciences Research 2014. ;1((4):):p. 113-8.

37. Gadissa B Hundie, S.R.V., Haagmans BL. Seroepidemiology of hepatitis $B$ and $C$ virus infections among blood donors in Ethiopia. Journal of Medical Virology January 2017.

38. Assefa A, Mathewos B, Alemu A, Addis Z, Alem M, M G. Hepatitis B and C viral infection among blood donors at Bahir Dar, Ethiopia. International Journal of Medical Research \& Health Sciences 2013;2 
(3):p. 624-30.

39. Habte $Y$, Seyoum B, Alemayehu T. Hepatitis $b$ virus infection and associated factors among blood donors at Dire Dawa, Eastern Ethiopia. J Antivir Antiretrovir 2016;8(4): p. 103-6.

40. Yami A, Alemseged $F$, Hassen A. Hepatitis $B$ and $C$ virus infections and their association with Human immunodeficiency: Across sectional study among blood donors in Ethiopia. Ethiop J Health Sci 2011;21(1):67-75.

\section{Tables}

Table 1: Socio-demographic characteristics of volunteer blood donors in Jimma Zone, South West Ethiopia, April 2018

\begin{tabular}{llll}
\hline Characteristic & Categories & Frequency & Percent (\%) \\
\hline \multirow{3}{*}{ Age in years } & $18-24$ & 334 & 60.9 \\
\cline { 2 - 4 } & 25- 34 & 174 & 31.8 \\
\cline { 2 - 4 } Sex & Male & 40 & 7.3 \\
\cline { 2 - 4 } & Female & 268 & 48.9 \\
\hline \multirow{3}{*}{ Marital status } & Single & 280 & 51.1 \\
\cline { 2 - 4 } & Married & 219 & 58.2 \\
\cline { 2 - 4 } & Separated & 18 & 38.5 \\
\hline Residence & Urban & 444 & 31.3 \\
\cline { 2 - 4 } & Rural & 104 & 19.0 \\
\hline \multirow{3}{*}{ Educational level } & Elementary & 16 & 2.9 \\
\cline { 2 - 4 } & Secondary & 162 & 29.6 \\
\cline { 2 - 4 } & College diploma & 159 & 29.0 \\
\cline { 2 - 4 } Degree and above & 211 & 38.5 \\
\hline \multirow{3}{*}{ Occupation } & Government employed & 130 & 23.7 \\
\cline { 2 - 4 } & Self-employed & 67 & 12.2 \\
\cline { 2 - 4 } & & 21 & 3.8 \\
\cline { 2 - 4 } & Daily laborer/ jobless & 21 & 60.2 \\
\cline { 2 - 4 } & Student & & \\
& & &
\end{tabular}

Table 2: Prevalence of HBsAg by socio-demographic characteristics of volunteer blood donors in Jimma Zone, South West Ethiopia, April 2018 


\begin{tabular}{|c|c|c|c|c|c|}
\hline \multirow[t]{2}{*}{ Variable } & \multirow[t]{2}{*}{ Category } & \multicolumn{2}{|c|}{ HBsAg Infection Status } & \multirow[t]{2}{*}{ COR(95\%CI ) } & \multirow[t]{2}{*}{ P-value } \\
\hline & & Positive (\%) & Negative (\%) & & \\
\hline \multirow{3}{*}{ Age group (in years) } & 18- 24 & $5(1.5)$ & $329(98.5)$ & $0.19(0.04-0.82)$ & $0.026^{*}$ \\
\hline & $25-34$ & $8(4.6)$ & $166(95.4)$ & $0.59(0.15-2.35)$ & 0.458 \\
\hline & $\geq 35$ & $3(7.5)$ & $37(92.5)$ & 1 & \\
\hline \multirow{2}{*}{ Sex } & Male & $12(4.5)$ & $256(95.5)$ & $3.23(1.03-10.16))$ & $0.044^{*}$ \\
\hline & Female & $4(1.4)$ & $276(98.6)$ & 1 & \\
\hline \multirow{3}{*}{ Marital status } & Single & $8(2.5)$ & $311(97.5)$ & $0.44(0.53-3.70)$ & 0.448 \\
\hline & Married & $7(3.3)$ & $204(96.7)$ & $0.58(0.068-5.02)$ & 0.624 \\
\hline & Separated & $1(5.6)$ & $17(94.4)$ & 1 & \\
\hline \multirow{2}{*}{ Residence } & Urban & $14(3.2)$ & $430(96.8)$ & $1.66(0.32-7.42)$ & 0.507 \\
\hline & Rural & $2(1.9)$ & $102(98.1)$ & 1 & \\
\hline \multirow{4}{*}{ Educational level } & Elementary & $0(0)$ & $16(100)$ & 0.000 & 0.999 \\
\hline & Secondary & $5(3.1)$ & 157(96.9) & $0.93(0.289-2.99)$ & 0.640 \\
\hline & Diploma & $4(2.5)$ & $155(97.5)$ & $0.75(0.216-2.62)$ & 0.654 \\
\hline & Degree and above & $7(3.3)$ & 204(96.7) & 1 & \\
\hline \multirow{4}{*}{ Occupation } & Employed & $6(4.6)$ & $124(95.4)$ & $2.23(0.74-6.77)$ & 0.256 \\
\hline & Self employed & $2(3.0)$ & $65(97.0)$ & $1.42(0.29-6.99)$ & 0.666 \\
\hline & Daily laborer & $1(4.8)$ & $20(95.2)$ & $2.31(0.271-19.68)$ & 0.445 \\
\hline & Student & $7(2.1)$ & $323(97.9)$ & 1 & \\
\hline
\end{tabular}

Note: $*=$ P-value $<0.25$, COR= Crude Odds Ratio

Table 3: Multivariable logistic regression analyses of the factors associated with HBsAg among volunteer blood donors in Jimma Zone, South West Ethiopia, April 2018 


\begin{tabular}{|c|c|c|c|c|c|c|}
\hline \multirow[t]{2}{*}{ Variable } & \multirow[t]{2}{*}{ Category } & \multicolumn{2}{|c|}{ HBsAg Status } & \multirow[t]{2}{*}{ COR(95\%CI } & \multirow[t]{2}{*}{ AOR(95\%CI ) } & \multirow{2}{*}{$\begin{array}{l}\mathrm{P}- \\
\text { value }\end{array}$} \\
\hline & & Positive & Negative & & & \\
\hline \multirow[t]{3}{*}{$\begin{array}{l}\text { Age group } \\
\text { (years) }\end{array}$} & $18-24$ & 5 & 329 & $\begin{array}{l}0.19(0.04- \\
0.82)\end{array}$ & $\begin{array}{l}0.17(0.36- \\
0.78)\end{array}$ & $0.022^{*}$ \\
\hline & $25-34$ & 8 & 166 & $\begin{array}{l}0.59(0.15- \\
2.35)\end{array}$ & $\begin{array}{l}0.53(0.13- \\
2.24)\end{array}$ & 0.391 \\
\hline & $\geq 35$ & 3 & 37 & 1 & 1 & \\
\hline \multirow[t]{2}{*}{ Sex } & Male & 12 & 256 & $\begin{array}{l}3.19(1.02-1 \\
.01)\end{array}$ & $\begin{array}{l}3.28(1.01- \\
10.68)\end{array}$ & $0.049^{*}$ \\
\hline & Female & 4 & 276 & 1 & 1 & \\
\hline \multirow[t]{2}{*}{ blood donation } & Repeated & 5 & 308 & $\begin{array}{l}0.33(0.11- \\
0.97)\end{array}$ & $\begin{array}{l}0.25(0.08- \\
0.76)\end{array}$ & $0.015^{*}$ \\
\hline & $\begin{array}{l}\text { First } \\
\text { time }\end{array}$ & 11 & 224 & 1 & 1 & \\
\hline \multirow[t]{2}{*}{$\begin{array}{l}\text { Unsafe therapeutic drug } \\
\text { injection }\end{array}$} & Yes & 3 & 20 & $\begin{array}{l}5.91(1.56-22 \\
39)\end{array}$ & $\begin{array}{ll}6.98 & (1.67- \\
29.30) & \end{array}$ & $0.08^{*}$ \\
\hline & No & 13 & 512 & 1 & 1 & \\
\hline
\end{tabular}

Note: *=Statistically significant $(\mathrm{P}$-value $<0.005$ ) 